\title{
Nutrients Modulate T1r2 Transcript Levels in MIN 6 and Primary Cultured Taste Buds Cells under High Glucose Condition
}

\author{
Shin-ichi Nakmura, Tetsuya Ookura \\ Division of Food Function, National Food Research Institute, National Agricultural and Food Research \\ Organization, Tsukuba, Japan \\ Email: ookura@affrc.go.jp
}

Received 22 February 2016; accepted 25 April 2016; published 28 April 2016

Copyright (C) 2016 by authors and Scientific Research Publishing Inc.

This work is licensed under the Creative Commons Attribution International License (CC BY). http://creativecommons.org/licenses/by/4.0/

c) (i) Open Access

\begin{abstract}
The sweet taste receptors comprised of T1r2 and T1r3, sense glucose concentrations in the gastrointestine. While hyperglycemia was reported to decrease the T1R2 and T1R3 tanscript levels in healthy subjects, no change was observed in type 2 diabetes patients. We investigated which glucose level and nutrients affect those transcript levels in MIN 6 and primary cultured taste buds cells using quantitative Reverse Trancription Polymerase Chain Reaction. High glucose diminished T1r2 transcript levels in MIN 6 and primary cultured taste buds cells. Resveratrol and its analogue augmented transcript levels of T1r1 and T1r2 above normal levels in MIN 6 cells in the medium with $25 \mathrm{mM}$ glucose. Adenine, but not guanine, augmented T1r2 transcript levels of MIN 6 cells in the medium with $25 \mathrm{mM}$ glucose. These results imply that nutrients in meals could affect sweet taste sensitivity by modulating T1r2 transcript levels in response to blood glucose levels.
\end{abstract}

\section{Keywords}

Glucose, T1r2, MIN6, Primary Culture, Taste Buds

\section{Introduction}

The sweet taste receptors comprised of T1r2 and T1r3, sense glucose concentrations in tongue, pancreas and intestine. During a meal, the receptor on the taste cells in tongues transduces the sweet taste response to brain through sensory nerves [1]. In pancreas, $\beta$-cells excrete insulin when the receptors sense the rise of blood glucose levels. In intestine, solitary tract or brush border cells, which express the sweet taste receptors, sense the intestinal glucose level to promote absorption of glucose at brush border cells [2]. 
Young et al. reported that the duodenal expression levels of T1R2 and T1R3 in subjects with type 2 diabetes was inversely correlated with their blood glucose levels [3]. Furthermore, they reported that hyperglycemia decreased the T1R2 and T1R3 levels in healthy subjects. No change was observed in type 2 diabetes patients [3]. Meanwhile, the murine MIN 6 cell lines, one of the pancreatic $\beta$-cell models [4], retain T1r3 expression under high glucose medium conditions [5]. However, the mechanisms for how glucose concentration regulates transcription of the sweet receptors are poorly understood.

In this report, we first examine which glucose concentrations affect the transcript levels of T1r1, T2r2 and T1r3 using the MIN 6 cell lines and primary cultured taste bud cells from mice tongues.

In southern European countries, wheat bread - one of staple food with higher glycemic index —is usually taken with red wine. Resveratrol is a plant-derived antioxidant, which is contained in grapes and red wine. In INS-1-1E $\beta$-cells-another insulin secreting cell lines upon glucose stimulation-resveratrol was reported to potentiate insulin-secretion in the medium with the $15 \mathrm{mM}, 20 \mathrm{mM}$ and $30 \mathrm{mM}$ glucose concentrations through the adenine mononucleotide-activated protein kinase (AMPK) pathway [6]. Resveratrol has also been shown to prevent type 2 diabetes by increasing insulin sensitivity [7] [8] and/or by decreasing IGF-1 [9] [10], and to protect neurodegeneration [11] probably through the AMPK [9] and other pathways [12] [13].

In Japan, rice-another staple food with higher glycemic index-is usually taken with soybean, especially as miso-soup. Adenine is known to be rich in soybean [14]. Adenine and adenine-related compounds are reported to modulate AMPK activity [15] [16], and resveratrol was reported to increase the amounts of adenine-nucleotidetriphosphate (ATP) and those of guanine-nucleotide-triphosphate (GTP) in Neuro 2A cell lines [12]. The effects of resveratrol and adenine-related compounds on the expression of sweet receptors remained unknown. We, thus, investigate these compounds effects on transcript levels of T1r2 in the medium with high glucose concentrations.

\section{Materials and Methods}

\subsection{Reagents and Animals}

Glucose, adenine, guanine, thymine, and cytosine were purchased from Wako Pure Chemicals (Osaka, Japan). RSVA314 was purchased from EMD Millipore (Billerica, MA). Resveratrol and 5-aminoimidazole-4-carboxamide $1-\beta$-D-ribonucleoside (AICAR) was purchased from Sigma (St. Louis, MOs). The animals used in this study were 8 to 16 weeks old male C57BL/6N mice fed with CE-2 containing 20\% lactose, 2\% calcium and 1.25\% phosphate (Nihon CLEA, Tokyo, Japan) under the $12 \mathrm{~h}$ light: $12 \mathrm{~h}$ dark condition. Mice were purchased from Charles River Japan (Yokohama, Japan) and bred at the National Food Research Institute, Tsukuba, Japan. We followed the guidelines of our organization for the care and their use of experimental animals. Dissected tongues were used in the following experiments.

\subsection{Cell Culture}

MIN 6 cells were grown in Dulbecco's modified Eagle’s medium (25 mM glucose, Gibco, Grand Island, NY) equilibrated with $5 \% \mathrm{CO}_{2}$ and $95 \%$ air at $37^{\circ} \mathrm{C}$. The medium was supplemented with $10 \%$ fetal bovine serum (Sigma), $0.25 \mu \mathrm{g} / \mathrm{ml}$ fungizone (Gibco), $50 \mathrm{mg} / \mathrm{ml}$ streptomycin (Meiji Seika, Tokyo, Japan) and $50 \mathrm{U} / \mathrm{ml}$ penicillin sulphate (Meiji Seika). MIN 6 cells were passaged with trypsin-EDTA and used between 22 - 30 passages.

\subsection{Primary Taste Buds Cell Culture}

Primary cell culture of taste buds cells from mice circumvallate and foliate papillae was performed as previously described [17] with modifications. Briefly, epithelial sheets of circumvallate and foliate papillae were prepared using Dispase II (dissolved in HBSS at $13.3 \mathrm{mg} / \mathrm{ml}$ : Eidia, Tokyo, Japan). The epithelial sheet was cut into small pieces and collected by centrifugation for $5 \mathrm{~min}$ at $310 \times \mathrm{g}$. After centrifugation, the small pieces were seeded on 24-well culture plate (BD Falcon, Franklin Lakes, NJ) coated with collagen type I (Nitta Gelatin, Osaka, Japan) at $300 \mu \mathrm{g} / \mathrm{ml}$, and grown at $37^{\circ} \mathrm{C}$ with $5 \% \mathrm{CO}_{2}$. Culture medium was QM12 (Research Institute for the Functional Peptide Co., Yamagata, Japan) supplemented with 5\% FBS (Sigma), 5 mM glucose, $0.2 \mu$ M hydrocortisone (Sigma), $0.1 \%$ (w/v) sericine (Wako Chemicals), $0.1 \mu \mathrm{g} / \mathrm{ml}$ heparin (Naclai tesque), $5 \mathrm{ng} / \mathrm{ml} \mathrm{EGF} \mathrm{(Sigma),}$ $0.25 \mu \mathrm{g} / \mathrm{ml}$ fungizone, $50 \mathrm{mg} / \mathrm{ml}$ streptomycin and $50 \mathrm{U} / \mathrm{ml}$ penicillin sulphate and $3 \mathrm{nM}$ insulin (Wako Pure Chemicals). 


\subsection{Glucose Stimulation of MIN6 Cells and Primary Cultured Taste Buds Cells}

MIN 6 cells $\left(1 \times 10^{6}\right)$ were cultured on a 12-well plate (BD Falcon) in the medium with $25 \mathrm{mM}$ glucose for $16 \mathrm{~h}$. The cells were treated with various glucose concentration (5, 10 and $25 \mathrm{mM}$ ) DMEM in the presence of stimulatory substances for $24 \mathrm{~h}$. The cells were subjected to the RNA extraction.

For primary cultured taste buds cells, culture medium was changed with the QM12 medium (5 mM Glucose) after 60 - $65 \mathrm{~h}$ when the cells had attached to the collagen-coated plates. Sixteen h later, the medium was replaced with QM12 medium (5, 10, and $25 \mathrm{mM}$ glucose) for $3 \mathrm{~h}$ in the absence of stimulatory substances-for 24 $\mathrm{h}$ in the presence of stimulatory substances. The cells in each well were subjected to the RNA extraction.

\subsection{RNA Extraction and Reverse Transcription Polymerase Chain Reaction (RT-PCR)}

Total RNAs from MIN 6 and primary cultured taste buds cells were isolated with TRI Reagent (Molecular Research Center, Cincinnati, OH) or with FavorPrep total RNA Extraction Column (Favorgen Biotech Corp, Ping-Tung, Taiwan) following the manufacturers' instructions. The total RNAs were transcribed into cDNA using ReveTra Ace qPCR RT Kit (Toyobo, Tokyo, Japan). For Real-time PCR analysis, reactions were performed in an ABI PRISM 7000 Sequence Detection System (Applied Biosystems, Foster City, CA) using THUNDERBIRD SYBR qPCR Mix (Toyobo). Each reaction was run in triplicate with $200 \mathrm{nM}$ primers in a volume of $20 \mu \mathrm{l}$. Reaction conditions were as follows: an initial denaturation for 1 min at $95^{\circ} \mathrm{C}$, followed by 40 cycles of $15 \mathrm{sec}$ at $95^{\circ} \mathrm{C}$, $45 \mathrm{sec}$ at $60^{\circ} \mathrm{C}$. In each experiment, melting curve analysis was carried out at the end of the PCR program to confirm specific amplification of target genes. Relative gene expression value was calculated by the comparative Ct method. Primers used in this study are listed in Table 1.

TATA-box binding protein (Tbp) was used as a reference gene for MIN 6. $\mathrm{IP}_{3} \mathrm{r}_{3}$ was used for primary cultured taste buds cells to minimize difference of each well in T1r2 expressing cell population.

\subsection{Statistical Analysis}

All the data are averages of, at least, three independent experiments and bars represent standard deviation of the means. For statistical analyses, multiple comparisons were performed by Dunnett's test. Statistical analyses were conducted with the statistical programming language R. Statistical significance was considered when the p-value was less than 0.05 or 0.01 .

\section{Results}

\subsection{Glucose Concentrations Regulated T1r1 and T1r2 Expression}

MIN 6 cells were maintained and passaged in high glucose $(25 \mathrm{mM})$ medium. We thus analyzed what medium glucose concentrations affect T1r1, T1r2 and T1r3 mRNA expression in MIN 6 cells. As shown in Figure 1, the levels of T1r1 and T1r2 transcript were significantly lower in the medium with $25 \mathrm{mM}$ glucose medium than in those with $5 \mathrm{mM}$ glucose medium. In contrast, T1r3 transcript levels did not change among 5, 10 and $25 \mathrm{mM}$

Table 1. Oligonucleotide primers for the quantitative RT-PCR.

\begin{tabular}{|c|c|c|c|}
\hline Gene & Primer sequence (strand) & Product size (bp) & Cycle (times) \\
\hline \multirow{2}{*}{ IP3r3(qPCR) } & 5'-TGTGCGTGTCCAACCGTATC-3' (+) & \multirow{2}{*}{124} & \multirow{2}{*}{40} \\
\hline & 5'-TGAGCCATCTCCTTCACTGG-3' (-) & & \\
\hline \multirow{2}{*}{ Tbp (qPCR) } & 5'-АСССТТСАССАATGACTCСТАTG-3' (+) & \multirow{2}{*}{190} & \multirow{2}{*}{40} \\
\hline & 5'-ATGATGACTGCAGCAAATCGC-3' (-) & & \\
\hline \multirow{2}{*}{ T1r1 (qPCR) } & 5'-CTGCCAAAGGACAGAATCCTC-3' (+) & \multirow{2}{*}{178} & \multirow{2}{*}{40} \\
\hline & 5'-GAACCGCATGGCTTGGAAG-3' (-) & & \\
\hline \multirow{2}{*}{ T1r2 (qPCR) } & 5'-TGGCAGCTACTCAGGGAGAT-3' (+) & \multirow{2}{*}{155} & \multirow{2}{*}{40} \\
\hline & 5'-GAGTAGGAGGCGATGCTTTG-3' (-) & & \\
\hline \multirow{2}{*}{ T1r3 (qPCR) } & 5'-TGGGGGCCTCTTTGTGTCT-3' (+) & \multirow{2}{*}{117} & \multirow{2}{*}{40} \\
\hline & 5'-TGGGTTGTGTTCTCTGGTTGA-3' (-) & & \\
\hline
\end{tabular}




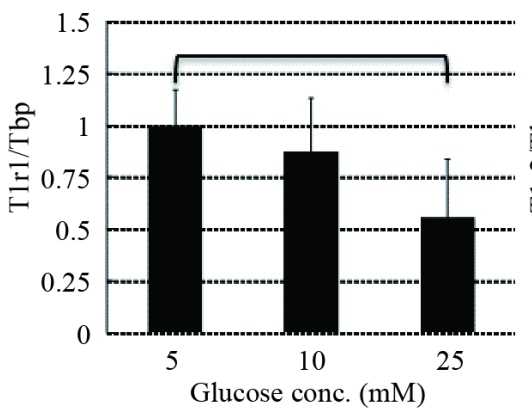

(a)

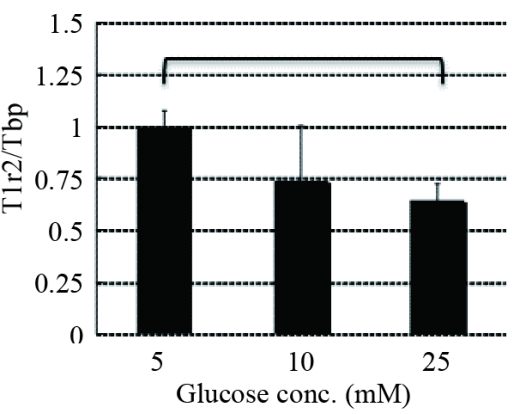

(b)

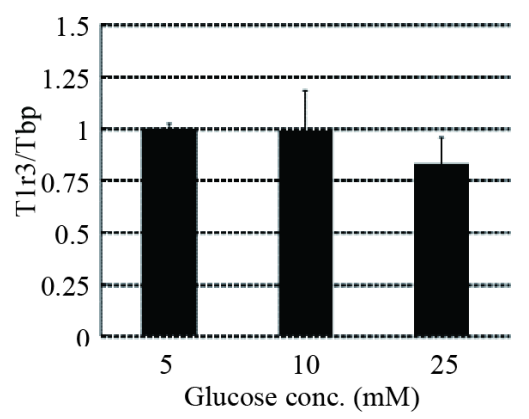

(c)

Figure 1. High glucose level significantly diminished T1r1 and T1r2 transcript levels of MIN6 cells (n=4). (a); T1r1, (b); T1r2, and (c); T1r3. * indicates significantly distinctive $\mathrm{p}<0.05$.

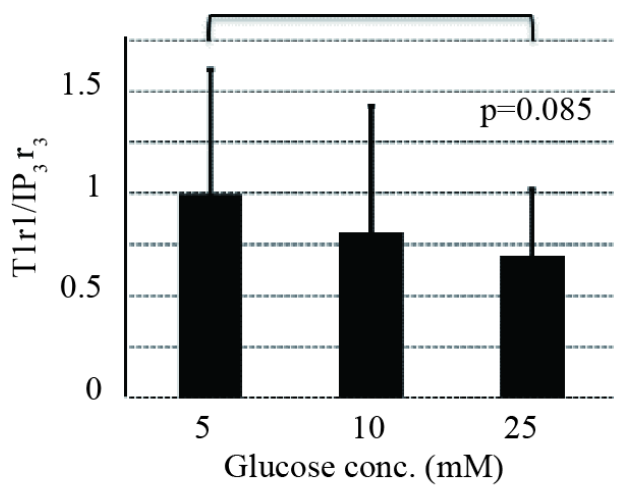

(a)

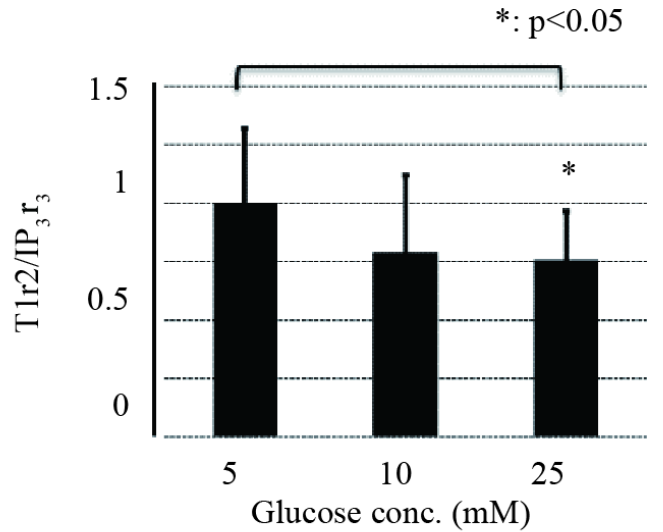

(b)

Figure 2. Glucose stimulation (3 hours) altered T1r1 (a) and T1r2 (b) transcript levels of the primary cultured taste buds cells $(\mathrm{n}=9)$. * indicates significantly distinctive $\mathrm{p}<0.05$.

glucose. To confirm the down regulation of T1r2 transcript levels in the presence of high glucose, we conducted additional experiments with the primary cultured taste buds cells.

\subsection{Glucose Effects in Primary Cultured Taste Buds Cells}

We analyzed the effect of increasing glucose concentrations on T1r1 and T1r2 mRNA expression in the primary cultured taste buds cells. While T1r1 transcript levels showed a tendency to decrease after $3 \mathrm{~h}$ of incubation as glucose levels were increased (Figure 2(a)), T1r2 transcript levels were significantly lower in the medium with $25 \mathrm{mM}$ glucose than those with $5 \mathrm{mM}$ glucose (Figure 2(b)).

During meal digestion, locally high glucose levels in tongues and in intestines might lower sweet sensitivity. Hypothesizing that the nutrients in meals could neutralize the above down-regulating effect of glucose concentrations during meal digestion, we analyzed nutrients to determine whether they could influence the effect of high glucose on T1r2 expression.

\subsection{Resveratrol and RSVA314 Effects on T1r's Expression}

We found that resveratrol and its analogue RSVA 314, which was reported to regulate energy flow via mitochondrial AMPK pathways, augmented T1r2 mRNA transcript levels (Figure 3). RSVA 314, but not resveratrol, increased T1r1 transcript levels in the medium with 25 mM glucose. However, neither compound altered transcript levels of T1r3 in the medium with $25 \mathrm{mM}$ glucose.

Figure 4 shows that resveratrol and RSVA314 increased T1r2 transcript levels in a dose dependent manner in MIN 6 cells. These augmenting effects were significant at $30 \mu \mathrm{M}$ (resveratrol) and $1 \mu \mathrm{M}$ (RSVA314). In the primary cultured taste buds cells, preliminary analysis with $3 \mu \mathrm{M}$ RSVA314 resulted in an inconsistent T1r2 expression between each experiment (data not shown). 
(a)

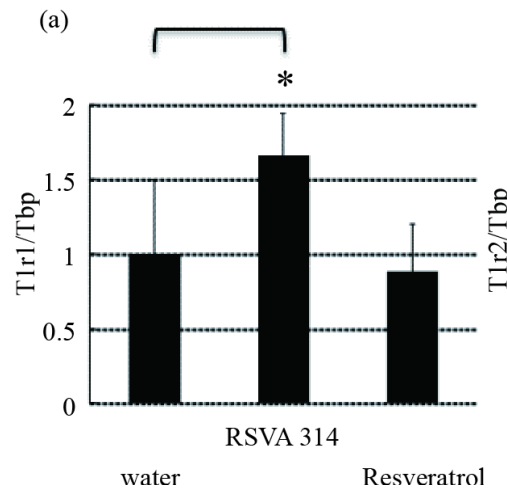

(b)

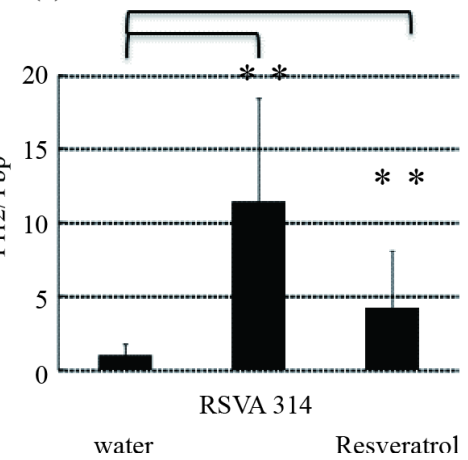

(c)

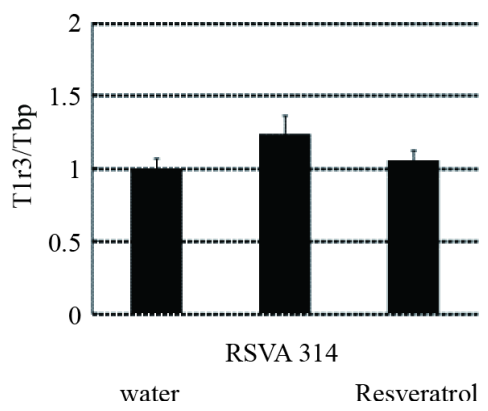

Figure 3. Resveratrol $(30 \mu \mathrm{M})$ and RSVA314 $(3 \mu \mathrm{M})$ altered T1r2 transcript levels of MIN 6 cells in the medium with 25 mM glucose. (a); T1r1 ( $=7),(b) ;$ T1r2 $(n=7)$, and $(c) ;$ T1r3 $(n=4) .{ }^{*}$ and $* *$ indicates significantly distinctive $\mathrm{p}<0.05$ and $\mathrm{p}<0.01$, respectively.

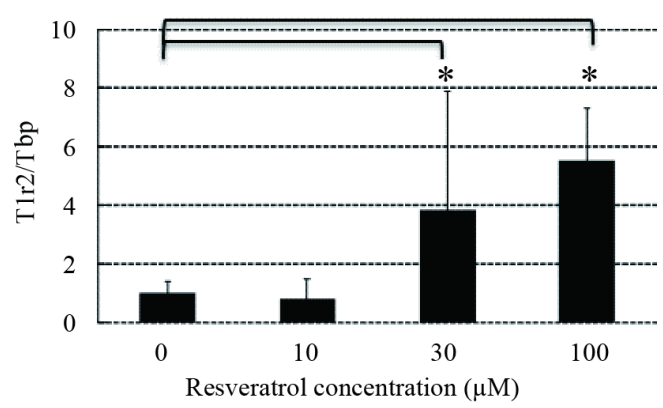

(a)

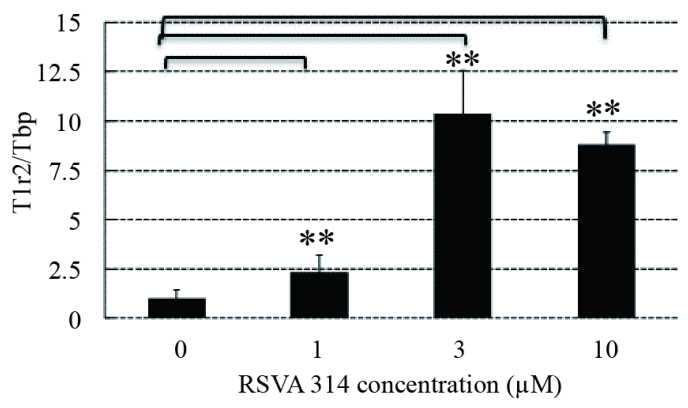

(b)

Figure 4. Resveratrol (a) and RSVA 314 (b) augmented T1r2 transcript levels of MIN 6 cells in a dose dependent manner in the medium with $25 \mathrm{mM}$ glucose $(\mathrm{n}=3)$. $*$ and $* *$ indicates significantly distinctive $\mathrm{p}<0.05$ and $\mathrm{p}<0.01$, respectively.

In the murine Neuro 2a cell line, resveratrol was reported to increase adenine nucleotide pools [12]. Next, we analyzed the effect of adenine-related compounds on T1r2 transcript levels of MIN 6 cells and the primary cultured taste buds cells.

\subsection{Adenine Augmented T1r2 Expression in MIN6 Cells}

Figure 5(a) shows that $1 \mathrm{mM}$ adenine augmented T1r2 transcript levels of MIN 6 cells in the medium with 25 mM glucose. Guanine, thymine, and cytosine did not alter the T1r2 transcript levels. Figure 5(b) shows that adenine $(3 \mathrm{mM})$ was likely to increase T1r2 transcript levels in primary cultured taste buds cells, even though the difference was not significant, perhaps due to a large variability in controls. Guanine, thymine and cytosine did not alter the T1r2 transcript levels.

\section{Discussion}

\subsection{High Glucose Concentration Effects on T1rs' Transcript Levels in MIN6 Cells}

The duodenal expression levels of T1R2 and T1R3 in type 2 diabetic subjects were inversely correlated with their blood glucose levels [3]. We first investigated whether glucose concentrations affected transcript levels of T1r's in MIN 6 cells, which express mRNA and protein of T1r3 [18]. Figure 1 shows that T1r1 and T1r2 transcript levels of MIN6 cells were significantly lower in the medium with $25 \mathrm{mM}$ glucose than in medium with 5 mM glucose. T1r3 transcript levels tended to decrease along the glucose concentration, even though the difference between $5 \mathrm{mM}$ and $25 \mathrm{mM}$ glucose was not significant at $\mathrm{p}<0.05$. These results were partially consistent with the report from Young [3], in which acute glucose perfusion lowered transcript levels of T1r2 but not that of T1r3. The longer exposure time (i.e. constant high glucose levels of the patients) might be required to significantly lower the T1r3 transcript levels. We thus examined the effect of glucose on T1r1 and T1r2 transcript levels in primary cultured taste buds cells. 




Figure 5. Adenine augmented T1r2 transcript levels in the medium with $25 \mathrm{mM}$ glucose in MIN 6 cells $(\mathrm{n}=4)(\mathrm{a})$ and in the primary cultured taste buds cells $(n=3)(b) . *$ indicates significantly distinctive $\mathrm{p}<0.05$.

\subsection{High Glucose Lowered T1r2 Expression in Primary Cultured Taste Buds Cells}

In a previous report, we used $4.75 \mu \mathrm{g} / \mathrm{ml}$ insulin for the primary taste buds cells culture [17]. At this insulin concentration, we were not able to detect T1r2 transcripts by qPCR (data not shown). Having reduced the insulin concentration to $3 \mathrm{nM}(0.0174 \mu \mathrm{g} / \mathrm{ml})$ in a stem cell oriented QM12 medium, we succeeded in culturing the taste buds cells which expressed T1r2 transcripts in accordance with glucose concentrations. Using this condition, we found that T1r2 transcript levels significantly decreased in the medium with $25 \mathrm{mM}$ glucose than that in the medium with 5 mM glucose (Figure 2(b)). T1r1 expression level was slightly lower in relation to increasing glucose concentration (Figure 2(a)), although the difference between $5 \mathrm{mM}$ and $25 \mathrm{mM}$ glucose was not significant at $\mathrm{p}<0.05$.

Hypothesizing that other nutrients in meals may modulate T1r2 expression during acute glucose rise, we analyzed the effect of resveratrol on T1r2 expression in MIN 6 cells, because resveratrol is known as effective against oxidative stress and diabetes [7].

\subsection{Resveratrol and RSVSA314 Augmented T1r2 Expression in MIN 6 Cells}

Figure 3 shows that resveratrol $(30 \mu \mathrm{M})$ and RSVA $314(3 \mu \mathrm{M})$ significantly augmented T1r2 expression but not T1r3 expression in 25 mM glucose. Figure 4 shows that the resveratrol (30 and $100 \mu \mathrm{M})$ and RSVA314 (1, 3 and $10 \mu \mathrm{M})$ significantly augmented T1r2 transcript levels in a dose-dependent manner. T1r2/T1r3 heterodimers had higher affinity against sugars than T1r3 homo-dimers [19]. This T1r2 augmenting effect of resveratrol and RSVA 314 may improve the glucose sensitivity of MIN 6 cells and affect glucose induced insulin secretion. In mice, resveratrol reduces levels of insulin, glucose, and IGF-1 levels in response to a high-calorie diet [9]. In a clinical trial of resveratrol, 90 days intake of resveratrol reduced the body weight and total insulin secretion [8]. Further studies are required to understand whether and if so, how this T1r2 augmenting effect of resveratrol may contribute to insulin secretion or insulin sensitivity under chronically high blood glucose levels.

\subsection{Adenine Augmented T1r2 Expression in MIN 6 Cells}

Adenine is rich in chicken liver (63.0 mg/100g), soybean (38.5 mg/100g), and dried mushroom (105.0 mg/100g) 
[14]. One mM of adenine augmented T1r2 transcript levels in the medium with $25 \mathrm{mM}$ glucose in MIN 6 cells, while guanine, thymine and cytosine had no effect (Figure 5(a)). Figure 5(b) shows that $3 \mathrm{mM}$ adenine tended to increase T1r2 transcript levels in the primary cultured taste buds cells, although the difference was not significant-perhaps due to of the high variability in controls.

In podocytes, high glucose negatively regulated AMP activated kinase (AMPK) [20], which is activated by an elevated AMP/ATP ratio. To elucidate augmenting effects of resveratrol and adenine on T1r2 expression, we preliminary tested 5-aminoimidazole-4-carboxamide 1- $\beta$-D-ribonucleoside (AICAR; putative AMPK activator). AICAR (1 mM) did not change the T1r2 transcript levels of MIN 6 in the medium with $25 \mathrm{mM}$ glucose (Nakamura and Ookura, unpublished data), suggesting that other pathways besides AMPK signaling may be involved in the glucose induced elevation of T1r2 expression. In Hep G2 cells, resveratrol (1 - $5 \mu \mathrm{M})$ was reported to stimulate NADH oxidation through mitochondrial complex I [13]. In Neuro 2a cells, $25 \mu \mathrm{M}$ resveratrol increased the levels of ATP and GTP without activating AMPK [13]. Further work will be needed to understand the mechanism for the influence of resveratrol and adenine on T1r2 expression.

\section{Conclusion}

High glucose concentration (25 mM) significantly diminished T1r2 transcript levels in MIN 6 and primary cultured taste buds cells with RT-PCR methods. Adenine and resveratrol augmented T1r2 transcript levels above normal levels in MIN 6 cells in the medium with $25 \mathrm{mM}$ glucose. These results imply that nutrients in meals could affect sweet taste sensitivity by modulating T1r2 transcript levels in response to blood glucose levels.

\section{Acknowledgements}

We are deeply grateful to Dr. Nancy E. Rawson for critical reading of the manuscripts and to Dr. Jun-ichi Miyazaki for providing us the MIN 6 cell lines. This work is in part supported from JST A-step grant to T. O.

\section{References}

[1] Nelson, G., Hoon, M.A., Chandrashekar, J., Zhang, Y., Ryba, N.J. and Zuker, C.S. (2001) Mammalian Sweet Taste Receptors. Cell, 106, 381-390. http://dx.doi.org/10.1016/S0092-8674(01)00451-2

[2] Dyer, J., Salmon, K.S., Zibrik, L. and Shirazi-Beechey, S.P. (2005) Expression of Sweet Taste Receptors of the T1R Family in the Intestinal Tract and Enteroendocrine Cells. Biochemical Society Transactions, 33, 302-305. http://dx.doi.org/10.1042/BST0330302

[3] Young, R.L., Sutherland, K., Pezos, N., Brierley, S.M., Horowitz, M., Rayner, C.K. and Blackshaw, L.A. (2009) Expression of Taste Molecules in the Upper Gastrointestinal Tract in Humans with and without Type 2 Diabetes. Gut, 58, 337-346. http://dx.doi.org/10.1136/gut.2008.148932

[4] Miyazaki, J., Araki, K., Yamato, E., Ikegami, H., Asano, T., Shibasaki, Y., Oka, Y. and Yamamura, K. (1990) Establishment of a Pancreatic Beta Cell Line That Retains Glucose-Inducible Insulin Secretion: Special Reference to Expression of Glucose Transporter Isoforms. Endocrinology, 127, 126-132. http://dx.doi.org/10.1210/endo-127-1-126

[5] Nakagawa, Y., Ohtsu, Y., Nagasawa, M., Shibata, H. and Kojima, I. (2014) Glucose Promotes Its Own Metabolism by Acting on the Cell-Surface Glucose-Sensing Receptor T1R3. Endocrine Journal, 61, 119-131. http://dx.doi.org/10.1507/endocri.EJ13-0431

[6] Vetterli, L., Brun, T., Giovannoni, L., Bosco, D. and Maechler, P. (2011) Resveratrol Potentiates Glucose-Stimulated Insulin Secretion in INS-1E Beta-Cells and Human Islets through a SIRT1-Dependent Mechanism. The Journal of Biological chemistry, 286, 6049-6060. http://dx.doi.org/10.1074/jbc.M110.176842

[7] Brasnyo, P., Molnar, G.A., Mohas, M., Marko, L., Laczy, B., Cseh, J., Mikolas, E., Szijarto, I.A., Merei, A., Halmai, R., Meszaros, L.G., Sumegi, B. and Wittmann, I. (2011) Resveratrol Improves Insulin Sensitivity, Reduces Oxidative Stress and Activates the Akt Pathway in Type 2 Diabetic Patients. The British Journal of Nutrition, 106, 383-389. http://dx.doi.org/10.1017/S0007114511000316

[8] Mendez-Del Villar, M., Gonzalez-Ortiz, M., Martinez-Abundis, E., Perez-Rubio, K.G. and Lizarraga-Valdez, R. (2014) Effect of Resveratrol Administration on Metabolic Syndrome, Insulin Sensitivity, and Insulin Secretion. Metabolic syndrome and Related Disorders, 12, 497-501. http://dx.doi.org/10.1089/met.2014.0082

[9] Baur, J.A., Pearson, K.J., Price, N.L., Jamieson, H.A., Lerin, C., Kalra, A., Prabhu, V.V., Allard, J.S., Lopez-Lluch, G., Lewis, K., Pistell, P.J., Poosala, S., Becker, K.G., Boss, O., Gwinn, D., Wang, M., Ramaswamy, S., Fishbein, K.W., Spencer, R.G., Lakatta, E.G., Le Couteur, D., Shaw, R.J., Navas, P., Puigserver, P., Ingram, D.K., de Cabo, R. and Sinclair, D.A. (2006) Resveratrol Improves Health and Survival of Mice on a High-Calorie Diet. Nature, 444, 337-342. 
http://dx.doi.org/10.1038/nature05354

[10] Jeon, B.T., Jeong, E.A., Shin, H.J., Lee, Y., Lee, D.H., Kim, H.J., Kang, S.S., Cho, G.J., Choi, W.S. and Roh, G.S. (2012) Resveratrol Attenuates Obesity-Associated Peripheral and Central Inflammation and Improves Memory Deficit in Mice Fed a High-Fat Diet. Diabetes, 61, 1444-1454. http://dx.doi.org/10.2337/db11-1498

[11] Lu, K.T., Ko, M.C., Chen, B.Y., Huang, J.C., Hsieh, C.W., Lee, M.C., Chiou, R.Y., Wung, B.S., Peng, C.H. and Yang, Y.L. (2008) Neuroprotective Effects of Resveratrol on MPTP-Induced Neuron Loss Mediated by Free Radical Scavenging. Journal of Agricultural and Food Chemistry, 56, 6910-6913. http://dx.doi.org/10.1021/jf8007212

[12] Nguyen, N.T., Ooi, L., Piller, S.C. and Munch, G. (2013) Proenergetic Effects of Resveratrol in the Murine Neuronal Cell Line Neuro2a. Molecular Nutrition \& Food Research, 57, 1901-1907. http://dx.doi.org/10.1002/mnfr.201300145

[13] Desquiret-Dumas, V., Gueguen, N., Leman, G., Baron, S., Nivet-Antoine, V., Chupin, S., Chevrollier, A., Vessieres, E., Ayer, A., Ferre, M., Bonneau, D., Henrion, D., Reynier, P. and Procaccio, V. (2013) Resveratrol Induces a Mitochondrial Complex I-Dependent Increase in NADH Oxidation Responsible for Sirtuin Activation in Liver Cells. The JOURNAL of Biological Chemistry, 288, 36662-36675. http://dx.doi.org/10.1074/jbc.M113.466490

[14] Science and Technology Agency, R.C. (2002) Standard Table of Food Composition in Japan Fifth Revised and Enlarged Edition-Appendix.

[15] Halse, R., Fryer, L.G., McCormack, J.G., Carling, D. and Yeaman, S.J. (2003) Regulation of Glycogen Synthase by Glucose and Glycogen: A Possible Role for AMP-Activated Protein Kinase. Diabetes, 52, 9-15. http://dx.doi.org/10.2337/diabetes.52.1.9

[16] Jaswal, J.S., Gandhi, M., Finegan, B.A., Dyck, J.R. and Clanachan, A.S. (2006) Effects of Adenosine on Myocardial Glucose and Palmitate Metabolism after Transient Ischemia: Role of 5'-AMP-Activated Protein Kinase. American Journal of Physiology: Heart and Circulatory Physiology, 291, H1883-H1892. http://dx.doi.org/10.1152/ajpheart.01147.2005

[17] Nakamura, S., Kawai, T., Kamakura, T. and Ookura, T. (2010) TGF-Beta3 Is Expressed in Taste Buds and Inhibits Proliferation of Primary Cultured Taste Epithelial Cells. In Vitro Cellular \& Developmental Biology-Animal, 46, 3644. http://dx.doi.org/10.1007/s11626-009-9239-9

[18] Medina, A., Nakagawa, Y., Ma, J., Li, L., Hamano, K., Akimoto, T., Ninomiya, Y. and Kojima, I. (2014) Expression of the Glucose-Sensing Receptor T1R3 in Pancreatic Islet: Changes in the Expression Levels in Various Nutritional and Metabolic States. Endocrine Journal, 61, 797-805. http://dx.doi.org/10.1507/endocrj.EJ14-0221

[19] Zhao, G.Q., Zhang, Y., Hoon, M.A., Chandrashekar, J., Erlenbach, I., Ryba, N.J. and Zuker, C.S. (2003) The Receptors for Mammalian Sweet and Umami Taste. Cell, 115, 255-266. http://dx.doi.org/10.1016/S0092-8674(03)00844-4

[20] Eid, A.A., Ford, B.M., Block, K., Kasinath, B.S., Gorin, Y., Ghosh-Choudhury, G., Barnes, J.L. and Abboud, H.E. (2010) AMP-Activated Protein Kinase (AMPK) Negatively Regulates Nox4-Dependent Activation of p53 and Epithelial Cell Apoptosis in Diabetes. The Journal of Biological Chemistry, 285, 37503-37512. http://dx.doi.org/10.1074/jbc.M110.136796 